\title{
Comparison of reendothelialization and neointimal formation with stents coated with antibodies against endoglin and CD34 in a porcine model
}

\author{
This article was published in the following Dove Press journal: \\ Drug Design, Development and Therapy \\ 17 April 2015 \\ Number of times this article has been viewed
}

\author{
Song Cuil,* \\ Xian-Tao Song' \\ Chao Ding 2 ,* \\ Li-Jun Meng ${ }^{3}$ \\ Shu-Zheng Lv' \\ Kefeng $\mathrm{Li}^{4,5}$ \\ 'The Key Laboratory of Remodeling- \\ Related Cardiovascular Diseases, \\ Department of Cardiology, Anzhen \\ Hospital Affiliated to Capital \\ Medical University, Beijing, People's \\ Republic of China; ${ }^{2}$ Department \\ of Cardiology, Huimin People's \\ Hospital, Binzhou, People's \\ Republic of China, ${ }^{3}$ Department of \\ Cardiology, Binzhou Central Hospital, \\ Binzhou, People's Republic of China; \\ ${ }^{4}$ School of Medicine, University of \\ California, San Diego, CA, USA; \\ ${ }^{5}$ Tianjin SunnyPeak Biotech Co, Ltd, \\ Tianjin, People's Republic of China \\ *These authors contributed equally \\ to this work
}

Correspondence: Xian-Tao Song The Key Laboratory of RemodelingRelated Cardiovascular Diseases, Department of Cardiology, Anzhen Hospital Affiliated to Capital Medical University, No. 2, Anzhen Road, Chaoyang District, Beijing, 100029,

People's Republic of China

Tel +86 I0 6445698 I

Fax +86 1064453756

Email songxiantao@medmail.com.cn

Li-Jun Meng

Department of Cardiology, Binzhou Central Hospital, Binzhou 25I700,

People's Republic of China

Tel +865435325877

$\mathrm{Fax}+865435322880$

Email zxyymlj@I26.com

\begin{abstract}
Anti-CD34 coated stents are the only commercialized antibody-coated stents currently used for coronary artery diseases with various limitations. Endoglin plays important roles in the proliferation of endothelial cells and vascular remodeling and could be an ideal target surface molecule. The objective of this study was to investigate the efficacy of stents coated with antiendoglin antibodies (ENDs) in terms of endothelial recovery and the reduction of neointimal formation. The performance of ENDs was evaluated by comparing with stents coated with anti-CD34 antibodies (CD34s), sirolimus-eluting stents (SESs), and bare metal stents (BMSs). Stents were randomly assigned and placed in the coronary arteries of juvenile pigs. Histomorphometric analysis and scanning electron microscopy were performed after stent implantation. Our results showed at 14 days after stent implantation, the neointima area and percent area stenosis in ENDs and CD34s were remarkably decreased compared with those in BMSs and SESs $(P<0.05)$. Moreover, the percentage of reendothelialization was significantly higher in ENDs and CD34s than that in SESs or BMSs at both 7 and 14 days $(P<0.05)$. There was no difference in the neointima area, percent area stenosis, and percentage of reendothelialization in ENDs compared with CD34s. The artery injury and the inflammation scores were similar in all groups at both 7 and 14 days. Our results demonstrate that the performance of ENDs is similar to the commercial CD34s, without the disadvantages of CD34s, and both are better than SESs and BMSs. ENDs potentially offer an alternative approach to reduce restenotic process and enhance reendothelialization after stent implantation.
\end{abstract}

Keywords: endothelialization, restenosis, anti-CD34

\section{Introduction}

Coronary angioplasty is a procedure used to open the clogged heart arteries by placing stents to help widen the arteries. With the rapid advancement of interventional cardiology over the past decade, coronary angioplasty has become the treatment of choice for atherosclerotic coronary artery diseases. Small wire mesh metal tubes also called bare metal stents (BMSs) are commonly used in clinical angioplasty. The major limitation of angioplasty is in-stent restenosis (ISR), which is characterized by intimal hyperplasia and blood vessel renarrowing. ${ }^{1}$ In addition, BMSs placement might cause endothelial injury as well as deeper injury due to lacerations of the arterial wall. ${ }^{2}$

The emergence of drug-eluting stents has dramatically reduced the incidence of ISR. ${ }^{3,4}$ The drugs on the stents are released slowly to block cell proliferation and thus reduce restenosis. Sirolimus is an antibiotic with powerful antiproliferative and immunosuppressant properties. ${ }^{5}$ The sirolimus-eluting coronary stents (SESs) were approved 
by the US Food and Drug Administration in 2003. Clinical trials showed SESs to be remarkably effective in reducing angiographic restenosis and the rate of revascularization compared with BMSs. ${ }^{6}$ However, it was reported that SESs might delay reendothelialization. ${ }^{7,8}$ Recently, the high incidence of stent thrombosis has more commonly been linked to SESs than BMSs. Several factors have been associated with the stent thrombosis after SESs implantation, such as delayed healing, inflammation, and endothelial dysfunction. ${ }^{9}$

Antibody-coated stents represent a more recent development. These stents are coated with a layer of special antibodies, which allow the stents to grow into the tissue faster than drug-coated stents. So far, only a few antibody-coated stents have been tested. Stents coated with anti-human CD34 antibodies (CD34s) (Genous ${ }^{\mathrm{TM}}$ EPC capture stent) was the representative one. It was first developed by OrbusNeich (Fort Lauderdale, FL, USA) and shown to be safe and feasible in a clinical trial. ${ }^{10}$ Despite the clear benefits of CD34s, recent randomized, controlled trials found that the Genous stent showed a trend of higher rates of target vessel failure. Moreover, CD34-positive progenitor cells might differentiate into various other cell types such as macrophages, ${ }^{11}$ and CD34-negative mesenchymal cells can also differentiate into endothelial cells. ${ }^{12}$ These drawbacks limited the efficacy of the Genous stent, and thus create an urgent need for the development of new antibody-coated stents.

Endoglin (also known as CD105) is a type III accessory receptor for the transforming growth factor (TGF)- $\beta$ superfamily. ${ }^{13,14}$ Endoglin is highly expressed on the vascular endothelium in adults and expressed by the endocardium and fibroblasts in cardiac tissue. ${ }^{15}$ Endoglin is a critical mediator of cardiovascular health. Emerging evidence has shown that endoglin modulates cardiac development, remodeling, and myocardial infarction. ${ }^{16,17}$ Given the critical role of endoglin in maintaining cardiovascular homeostasis, it represents a potential unique therapeutic target for cardiovascular diseases. Several studies have demonstrated that vascular targeting by anti-endoglin antibody is a useful and safe procedure for tumor imaging and treatment in vitro and in vivo. ${ }^{18}$ Our previous study demonstrated that endoglin antibody-coated stents (ENDs) can significantly reduce restenosis and neointimal hyperplasia. ${ }^{19}$

In this study, we comprehensively evaluated the performance of ENDs and them compared with the commercial CD34s, SESs, and BMSs using the healthy coronary porcine model. Our results indicate that the performance of ENDs is similar to the commercial CD34s, without the disadvantages related to CD34s, and both are superior to SESs and BMSs. ENDs potentially offer an alternative approach to reduce the restenotic process after stent implantation and enhance reendothelialization.

\section{Materials and methods Materials}

A total of 40 domestic pigs (4- to 5-month-old, 25-35 kg) were purchased from the Agricultural University Experimental Animal Center (Beijing, People's Republic of China). Stainless steel stents coated with murine monoclonal ENDs and CD34s were purchased from Beijing Lepu Medical Technology limited corporation (Beijing, People's Republic of China). SESs were purchased from Johnson \& Johnson (New Brunswick, NJ, USA). BMSs were obtained from Abbott Laboratories (Abbott Park, IL, USA). Stents were randomized and placed in the left anterior descending circumflex or right coronary arteries (one or two stent per artery). The experiments were performed using an incomplete factorial design, which allows intraindividual and interindividual comparisons, and the pigs were randomly assigned to these treatment modalities. Pigs were treated with $75 \mathrm{mg}$ clopidogrel and $100 \mathrm{mg}$ aspirin daily. The animals were sacrificed at 7 and 14 days, and stents were then subjected to histological, scanning electron microscopy (SEM), or coronary angiographic examinations.

\section{Stent implantation and harvest}

All studies were conducted at Capital Medical University, in facilities accredited by the Association for Assessment and Accreditation of Laboratory Animal Care International under the Capital Medical University Institutional Animal Care and Use Committee-approved animal subjects protocols, and followed the National Institutes of Health Guidelines for the use of animals in research. All domestic pigs were treated using standard interventional techniques. The residual stenosis was kept less than $20 \%$ by visual assessment, with a thrombolysis in myocardial infarction flow grade rate of 3 , and postdilation was performed if needed. All domestic pigs were examined at 7 and 14 days after stent implantation to assess the anginal status and the occurrence of major adverse cardiac and cerebrovascular events.

The cross-sectional area of stenosis was collected and calculated using coronary intravascular ultrasound (IVUS). Briefly, before IVUS examination, heparin (100 U/kg) was intraarterially administered to the animals. IVUS examination was performed using a Jomed $30-\mathrm{MHz}$ catheter with 2.9Fr phased array probe (Invision Gold ${ }^{\mathrm{TM}}$; Jomed, Sweden). IVUS images were recorded on the compact disk for offline analysis. Cross sections obtained with IVUS were linked with the corresponding histologic sections. The percentage 
of cross-sectional area of stenosis was calculated by the following equation:

External elastic membrane area-Lumen area External elastic membrane area $\times 100 \%$

\section{Histomorphometric analysis}

At 7 and 14 days after stent implantation, pigs were euthanized using intravenous injection of pentobarbital solution $(100 \mathrm{mg} / \mathrm{kg})$, and the stented coronary arteries were collected. The arteries were then sectioned into 3-5 $\mathrm{mm}$ segments from the proximal, middle, and distal part of the stents and fixed in $4 \%$ formalin for 48 hours. A serial of $5 \mu \mathrm{m}$ sections from the distal part of the stents were subjected to hematoxylin and eosin staining as described by Li et al. ${ }^{20}$ The lumen area as well as the area circumscribed by the internal elastic lamina were measured using an Image-Pro Plus computer-assisted digital system (Media Cybernetics, Rockville, MD, USA). Neointima area (NA) was defined as internal elastic laminalumen area. The statistical analysis for treatment effects was conducted based on the average of all sections per stent.

\section{Scanning electron microscopy}

SEM analysis was performed as described previously. ${ }^{19}$ Briefly, intact stented arterial segments were fixed in 1.6\% glutaraldehyde, dried with liquid $\mathrm{CO}_{2}$, and coated with gold. The specimens were visualized using a Hitachi SEM (Model $3600 \mathrm{~N}$; Tokyo, Japan). The percent area of reendothelialization compared with the total luminal surface area was calculated. For each specimen, five SEM photomicrographs were taken at $\times 400$ magnification, and the reendothelialization area for each artery was represented by the sum of the data for the five photographed subareas. ${ }^{21}$

Stent endothelialization was assessed using the method described by the previous study. ${ }^{22}$ Stent endothelialization was scored by the extent of the circumference of the arterial lumen covered by endothelium: $1=25 \% ; 2=25 \%-75 \%$; and $3=75 \%-100 \%$ coverage, and data were expressed as averages of six independent scoring $(n=6)$.

\section{Evaluation of arterial injury and inflammation scores}

The severity of arterial injury was scored as previous described by Schwartz et $\mathrm{al}^{23}$ : $0=$ no injury; $1=$ break in the internal elastic membrane; $2=$ perforation of the media; and $3=$ perforation of the external elastic membrane to the adventitia. The inflammation score for each individual strut was graded according to the following criteria: $0=$ no inflammatory cells surrounding the strut; $1=$ light, noncircumferential lymphohistiocytic infiltrate surrounding strut; $2=$ localized, moderate to dense cellular aggregate surrounding the strut noncircumferentially; and $3=$ circumferential, dense lymphohistiocytic cell infiltration of the strut. Arterial injury and inflammation scores for each cross section was calculated by dividing the sum of the individual injury and inflammation scores by the total number of struts at the examined section, as previously described. ${ }^{23,24}$

\section{Statistical analysis}

Statistical analysis was performed with Graphpad prism 6 (La Jolla, CA, USA). The data are presented as mean \pm standard deviation. One-way ANOVA followed by Tukey's test was used for comparisons of the four stent groups. Significance was established at the $95 \%$ confidence level $(P<0.05)$.

\section{Results \\ Procedural characteristics}

A total of 120 stents including 30 BMSs, 30 SESs, 30 CD34s, and 30 ENDs were randomly placed in the proximal left anterior descending, proximal circumflex, and proximal right coronary artery for 40 pigs. No death was observed during this study. Quantitative coronary angiography before and after stent implantation indicated that stent-to-artery ratio was 1.1-1.2 for all 120 stented arteries. There was no significant difference in stent-to-artery ratio among the four stent groups (data not shown).

\section{Histomorphometric analysis}

Stent malapposition was not detectable in histologic specimens or by IVUS examination after stent implantation. As shown in Figure 1A, the average NA at 7 days after stent implantation was $0.97 \pm 0.14 \mathrm{~mm}^{2}, 0.92 \pm 0.12 \mathrm{~mm}^{2}, 0.95 \pm 0.09 \mathrm{~mm}^{2}$, and $0.91 \pm 0.07 \mathrm{~mm}^{2}$ for BMSs, SESs, CD34s, and ENDs, respectively $(P>0.05)$. No significant differences were also observed in the percent area stenosis among the four stent groups at 7 days (Figure 1B).

At 14 days after stent implantation, the average NA of ENDs, SESs and CD34s was significantly lower $(0.9 \pm 0.08$ $\mathrm{mm}^{2}, 0.95 \pm 0.12 \mathrm{~mm}^{2}$, and $0.88 \pm 0.06 \mathrm{~mm}^{2}$ ) than BMSs, which was $1.25 \pm 0.14 \mathrm{~mm}^{2}(P<0.05$, Figure $2 \mathrm{~B})$. The corresponding percent area stenosis was $23.80 \% \pm 4.00 \%, 24.20 \% \pm 2.20 \%$, $38.0 \% \pm 3.20 \%$, and $23.6 \% \pm 3 \%$ for ENDs, SESs, BMSs, and $\mathrm{CD} 34 \mathrm{~s}$, respectively. Importantly, percent area stenosis in ENDs, SESs, and CD34s were less than that in BMSs $(P<0.01$ for ENDs, SESs, and CD34s versus BMSs), whereas no differences in mean NA and percent area stenosis were observed between ENDs, SESs, and CD34s ( $P>0.05$ ) (Figure 2C). In addition, arterial injury and inflammation scores were similar in all four stent groups at 7 and 14 days $(P>0.05)$ (Figure 3$)$. 
A

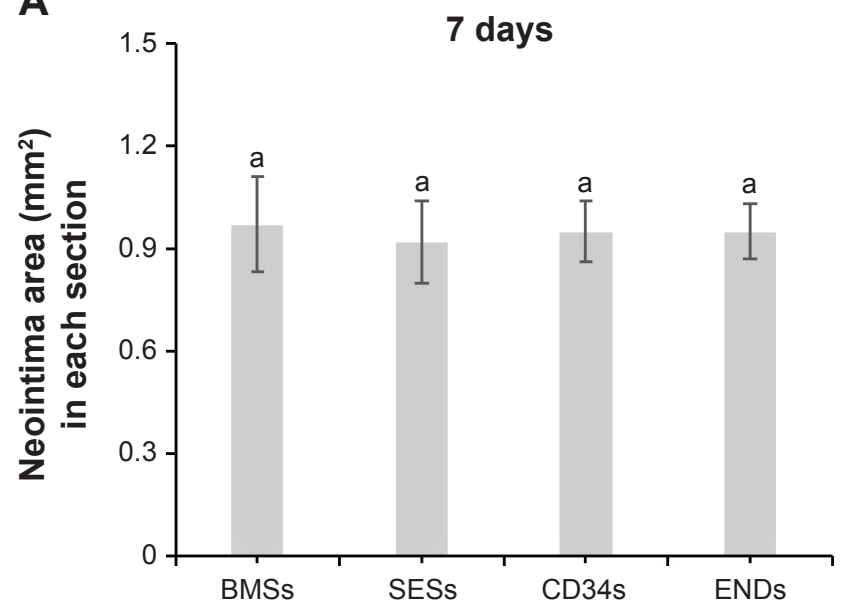

B

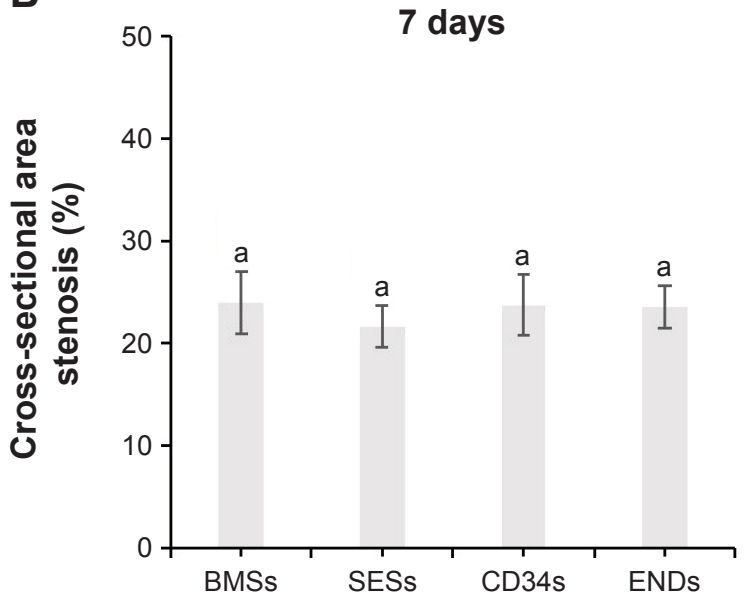

Figure I Histomorphometric analysis of stented coronary arteries at 7 days after stent implantation.

Notes: (A) Neointima area; (B) Percent area stenosis of stented arteries; Data represent the mean \pm SD ( $n=15$ ); Data indexed by same letter indicate no significant difference among the groups according to one-way ANOVA followed by Tukey's test $(P>0.05)$.

Abbreviations: BMSs, bare metal stents; CD34s, stents coated with anti-CD34 antibody; ENDs, stents coated with anti-endoglin antibody; SD, standard deviation; SESs, sirolimus-eluting stents.

\section{Evaluation of stent reendothelialization}

To determine the effect of coating stents with antibodies to endoglin on reendothelialization, stents coverage by endothelial cells were evaluated by SEM. At 7 days of poststent implantation, there was a significantly higher extent of endothelial coverage above struts in ENDs
$(60.63 \% \pm 5.60 \%)$ and $\mathrm{CD} 34 \mathrm{~s}(61.66 \% \pm 5.70 \%)$ compared with SESs $(35.82 \% \pm 4.95 \%)$ or BMSs $(41.30 \% \pm 6.80 \%)$ $(P<0.01)$ (Figure 4). At 14 days, the reendothelialization areas for all stents were higher, but ENDs $(94.64 \% \pm 6.90 \%)$ and CD34s $(95.61 \% \pm 6.80 \%)$ showed greatest endothelialization compared with BMSs $(75.61 \% \pm 7.87 \%)$ or SESs

\section{A BMSs}
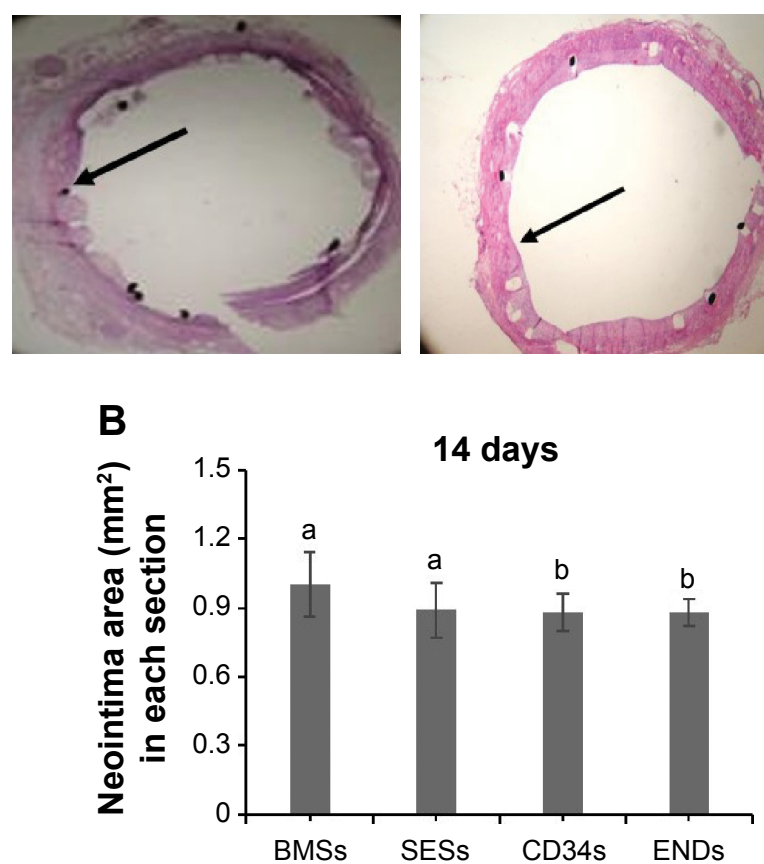

SESs
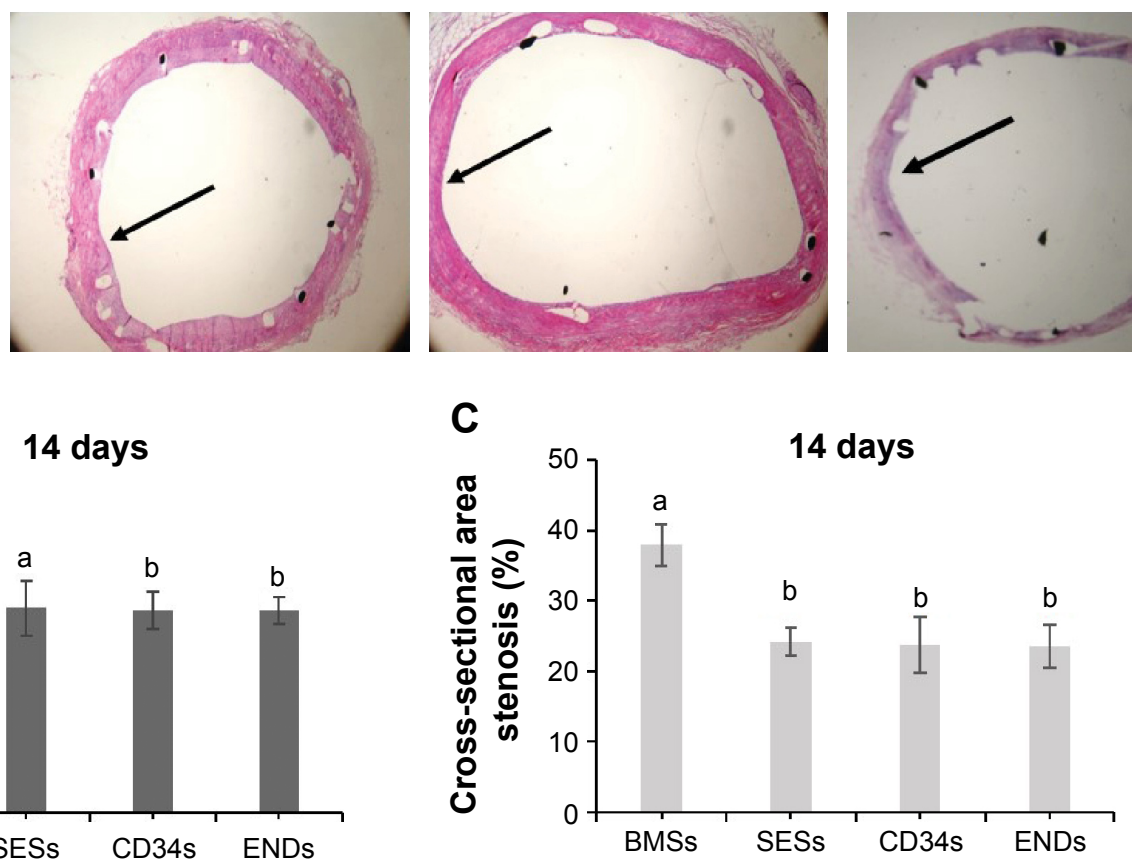

Figure 2 Histomorphometric analysis of stented coronary arteries at 14 days after stent implantation.

Notes: (A) Representative images of hematoxylin and eosin-stained cross sections of arteries (a) (magnification, $\times 40$ ); (B) Mean neointima area; (C) Percent area stenosis of stented arteries; Arrow indicate neointima; Data represent the mean \pm SEM $(n=15)$; Data indexed by different letters indicated significant difference among the groups according to one-way ANOVA followed by Tukey's test $(P<0.05)$.

Abbreviations: BMSs, bare metal stents; CD34s, stents coated with anti-CD34 antibody; ENDs, stents coated with anti-endoglin antibody; SEM, standard error of the mean; SESs, sirolimus-eluting stents. 

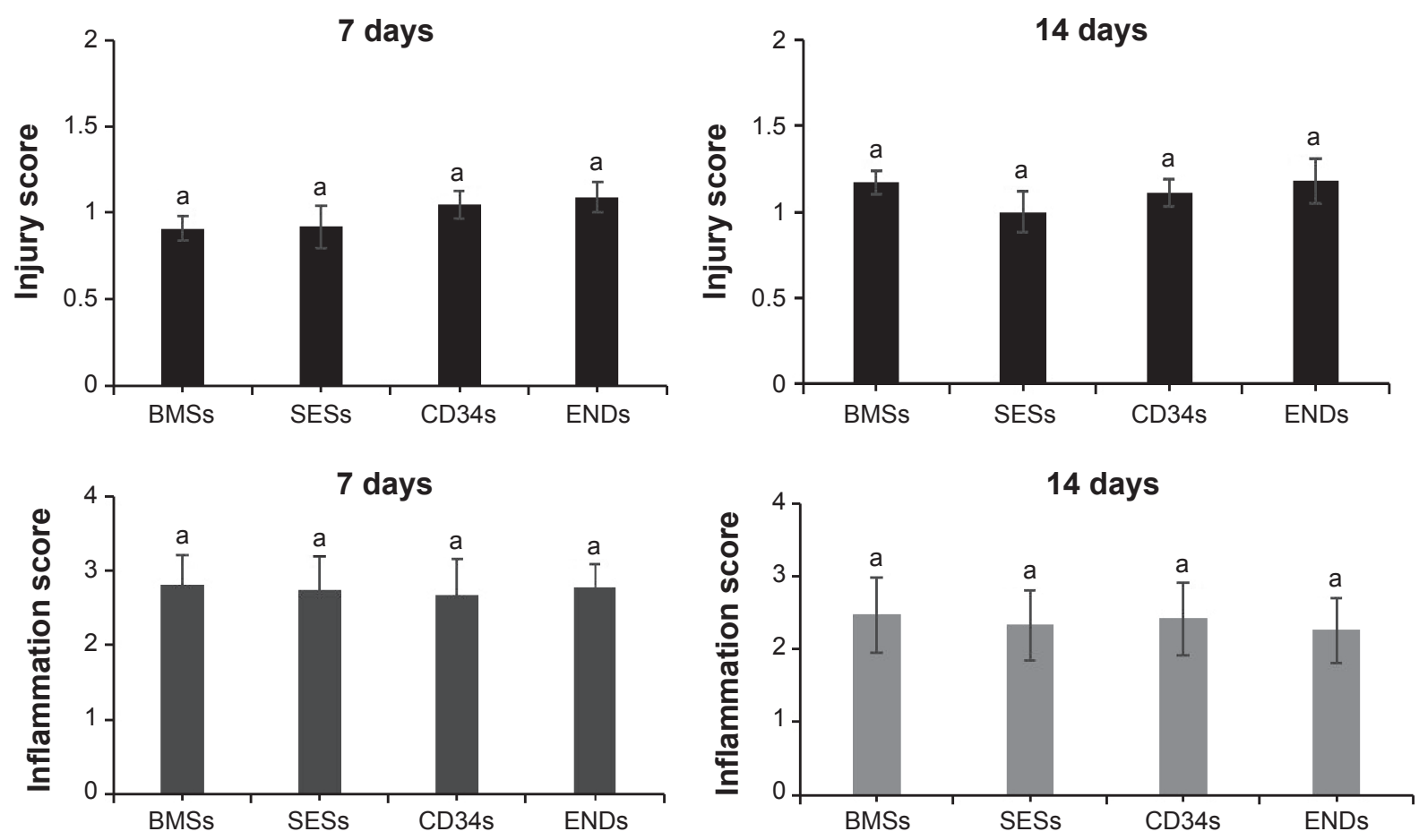

Figure 3 Quantification of artery injury and infiltration scores around the stent struts at 7 and 14 days after stent implantation.

Notes: Data represent the mean \pm SEM $(n=15)$; Data indexed by same letter indicated no significant difference among the groups according to one way ANOVA followed by Tukey's test. $P>0.05$.

Abbreviations: BMSs, bare metal stents; CD34s, stents coated with anti-CD34 antibody; ENDs, stents coated with anti-endoglin antibody; SEM, standard error of the mean; SESs, sirolimus-eluting stents.

A

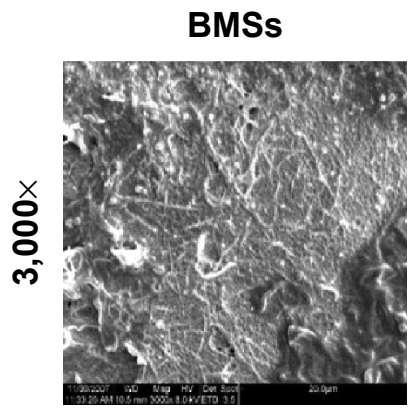

SESS

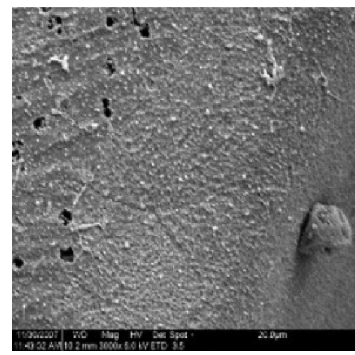

CD34s

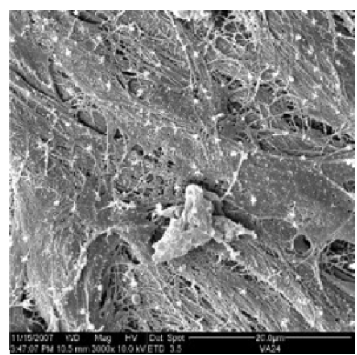

ENDs

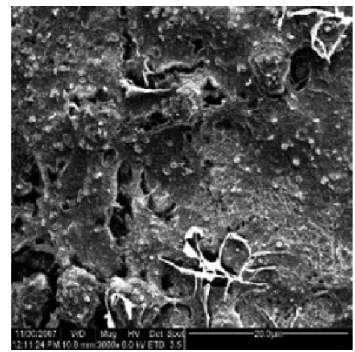

B

7 days
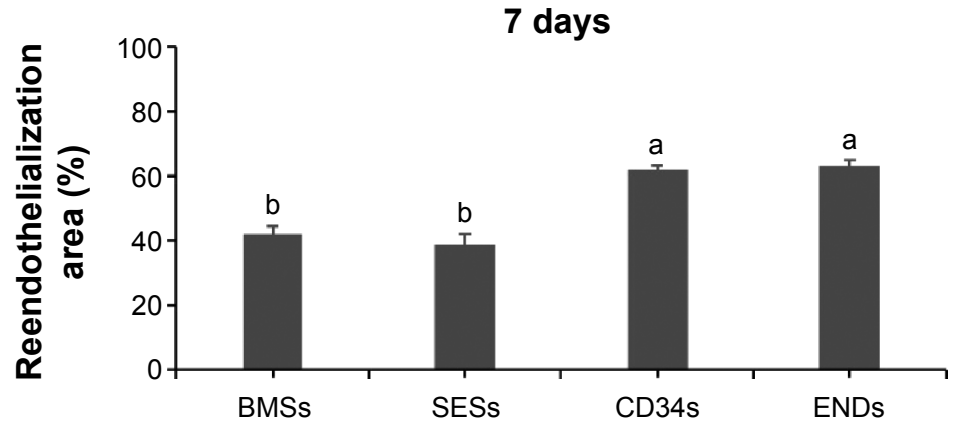

Figure 4 Reendothelialization of arteries assessed by scanning electron microscopy at 7 days poststent implantation.

Notes: (A) Scanning electron microscopy images of the intact stented arterial segments; (B) The percentage of reendothelialized area of total stented area; The scale bar on the images represent $500 \mu \mathrm{m}$; Data represent the mean \pm SEM $(n=15)$; Data indexed by different letters indicated significant differences among the four groups according to one-way ANOVA followed by Tukey's test $(P<0.05)$.

Abbreviations: BMSs, bare metal stents; CD34s, stents coated with anti-CD34 antibody; ENDs, stents coated with anti-endoglin antibody; SEM, standard error of the mean; SESs, sirolimus-eluting stents. 


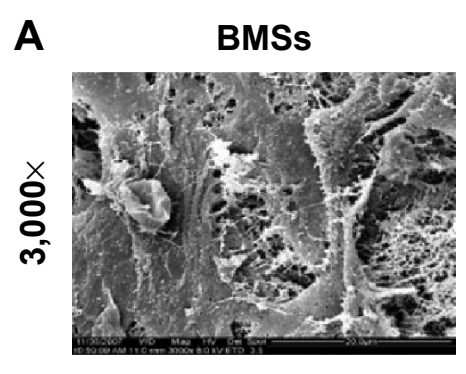

SESS

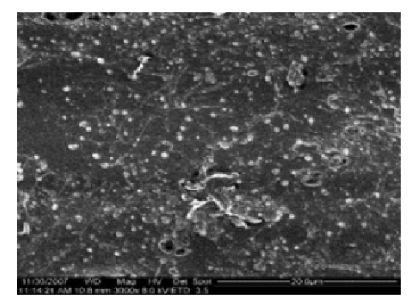

CD34s

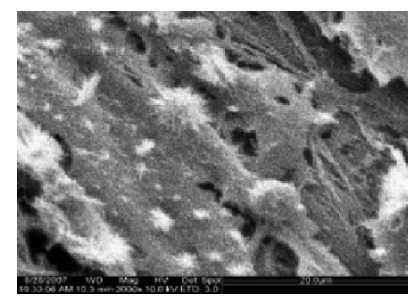

ENDs

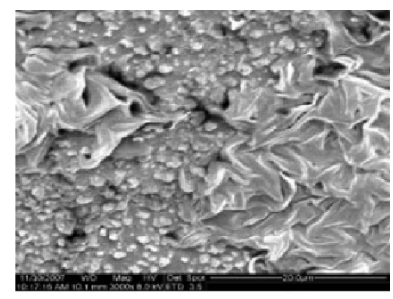

B

14 days

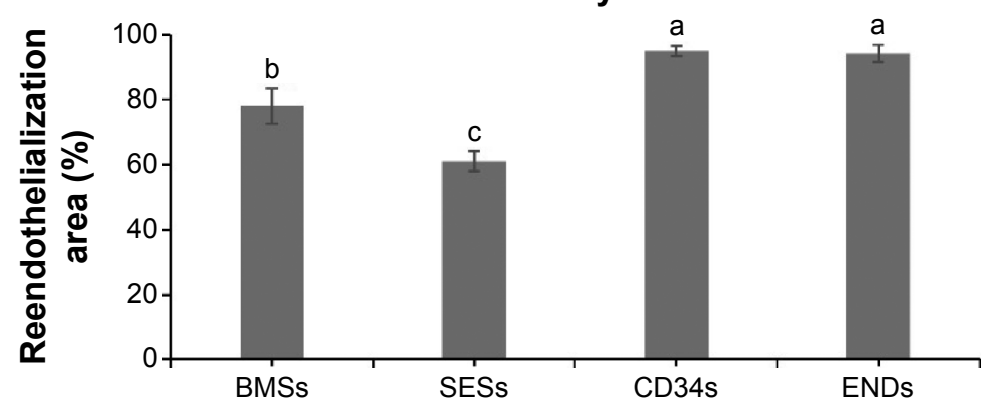

Figure 5 Reendothelialization of arteries assessed by scanning electron microscopy at 14 days poststent implantation.

Notes: (A) Scanning electron microscopy images of the intact stented arterial segments; (B) The percentage of reendothelialized area of total stented area; The scale bar on the images represented $500 \mu \mathrm{m}$; Data was mean \pm SEM ( $n=15)$; Data indexed by different letters indicated significant differences among the four groups according to one-way ANOVA followed by Tukey's test.

Abbreviations: BMSs, bare metal stents; CD34s, stents coated with anti-CD34 antibody; ENDs, stents coated with anti-endoglin antibody; SEM, standard error of the mean; SESs, sirolimus-eluting stents.

$(65.21 \% \pm 8.39 \%)(P<0.01)$ (Figure 5). There were no differences in the percentage of reendothelialization between ENDs and CD34s $(P>0.05)$ (Figures 4 and 5).

\section{Discussion}

Drug-eluting stents such as sirolimus- and paclitaxel-eluting stents have been successfully demonstrated to be effective in reducing ISR and neointimal hyperplasia. ${ }^{25,26}$ However, drug-eluting stents with nonselective drugs could potentially increase the risk of late stent thrombosis and inhibit smooth muscle cell proliferation. ${ }^{27,28}$ In regarding to next generation stents, great efforts have been placed on the development of antibody-coated stents. These stents are coated with a layer of special antibodies. So far, the Genous bioengineered $\mathrm{R}$ stent, coated with anti-CD34 antibodies through a biocompatible matrix, has been developed and commercialized. The anti-CD34 antibodies helped capture endothelial progenitor cells (EPCs) from circulation, thus facilitating stent endothelialization. ${ }^{29}$ Even though CD34s have clear advantages over BMSs and SESs, there have been concerns over the use of CD34 antibodies. ${ }^{11,12}$ CD34 is not a specific marker of EPCs but rather a pluripotent stem cell marker. CD34-positive cells are able to differentiate into various kinds of cells including inflammatory cells and vascular smooth muscle cells, and thus only a small portion of the CD34-positive cells are actually EPCs. ${ }^{30}$ Therefore, there is an urgent need to search for other antibody-coated stents.

Unlike CD34, endoglin belongs to the TGF- $\beta$ receptor family. ${ }^{13}$ Its mode of action is different from CD34. As part of TGF- $\beta$ receptor complex, endoglin controls proliferation, cellular differentiation, and other functions in most cells. ${ }^{31}$ In addition, endoglin is known to inhibit the biological effects of TGF- $\beta$ on synthesis of fibronectin and cell adhesion and aggregation. ${ }^{32}$ Importantly, endoglin has a role in the development of the cardiovascular system and in vascular remodeling and is emerging as a marker of activated endothelial cells. ${ }^{33}$ Moreover, endoglin overcomes some of the drawbacks of CD34. Unlike CD34, the vascular expression of endoglin is only limited to proliferating cells, and endoglin-negative mesenchymal cells cannot differentiate into endothelial cells. ${ }^{34}$

It was reported that $\mathrm{CD} 34 \mathrm{~s}$ accelerate stent reendothelialization. ${ }^{35}$ In this study, we showed that ENDs significantly promote reendothelialization compared with SESs and BMSs. No significant difference was observed between CD34s and ENDs in terms of reendothelialization of arteries and mean NA. Based on antigen-antibody binding principle, it is likely that ENDs might selectively capture EPCs and endothelial cells, leading to increased stent reendothelialization.

Restenosis, a narrowing of a blood vessel, is mainly characterized by neointimal hyperplasia. Endothelial denudation 
is considered to be the primary injury after stent implantation, and stent implantation might irritate or damage arterial walls and trigger neointimal hyperplasia of smooth muscle cells during the healing process. When larger areas are denuded or endothelial recovery is delayed, a higher degree of intimal thickening occurs. ${ }^{36}$ A previous study showed that CD34s drastically reduce rates of restenosis and thrombosis. ${ }^{37}$ Our results confirmed that the NA was significantly reduced in CD34s, which was similar to ENDs.

\section{Conclusion}

In this study, a comprehensive comparison of ENDs with the commercial CD34s, SESs, and BMSs was performed. Our results showed that ENDs could promote stent reendothelialization and reduce stenosis of stented arteries more effectively than SESs and BMSs. No significant difference was observed between ENDs and CD34s in terms of reendothelialization and the reduction of neointimal hyperplasia. Due to the limitations of CD34s, our study might provide a promising target for stent development to accelerate healing and reduce restenosis after stent implantation.

\section{Acknowledgments}

This study was supported by grants from the China Postdoctoral Science Foundation (SC, 20070410586), Beijing An Zhen Hospital Dean Foundation (SC, 2010F01), China National Natural Science Funds for Distinguished Young Scholar (HL, 81025001), Beijing High-Level Talent Program (HL, PHR20110507), and the National Science Foundation of China (31271065).

\section{Disclosure}

The authors report no conflicts of interest in this work.

\section{References}

1. Bennett MR. In-stent stenosis: pathology and implications for the development of drug eluting stents. Heart. 2003;89(2):218-224.

2. Scott NA. Restenosis following implantation of bare metal coronary stents: pathophysiology and pathways involved in the vascular response to injury. Adv Drug Deliv Rev. 2006;58(3):358-376.

3. Morice MC, Serruys PW, Sousa JE, et al; RAVEL Study Group. Randomized Study with the Sirolimus-Coated Bx Velocity Balloon-Expandable Stent in the Treatment of Patients with de Novo Native Coronary Artery Lesions. A randomized comparison of a sirolimus-eluting stent with a standard stent for coronary revascularization. $N$ Engl J Med. 2002; 346(23):1773-1780.

4. Stone GW, Ellis SG, Cox DA, et al; TAXUS-IV Investigators. Oneyear clinical results with the slow-release, polymer-based, paclitaxeleluting TAXUS stent: the TAXUS-IV trial. Circulation. 2004;109(16): 1942-1947.

5. Chang JY, Sehgal SN, Bansbach CC. FK506 and rapamycin: novel pharmacological probes of the immune response. Trends Pharmacol Sci. 1991;12(6):218-223.

6. Kirtane AJ, Leon MB. Clinical use of sirolimus-eluting stents. Cardiovasc Drug Rev. 2007;25(4):316-332.
7. Qiao Y, Bian Y, Yan X, Liu Z, Chen Y. Efficacy and safety of sirolimuseluting stents versus bare-metal stents in coronary artery disease patients with diabetes: a meta-analysis. Cardiovasc J Afr. 2013;24(7):274-279.

8. Rodriguez-Granillo A, Rubilar B, Rodriguez-Granillo G, Rodriguez AE. Advantages and disadvantages of biodegradable platforms in drug eluting stents. World J Cardiol. 2011;3(3):84-92.

9. Serruys PW, Kutryk MJ, Ong AT. Coronary-artery stents. NEngl J Med. 2006;354(5):483-495.

10. Garg S, Duckers HJ, Serruys PW. Endothelial progenitor cell capture stents: will this technology find its niche in contemporary practice? Eur Heart J. 2010;31(9):1032-1035.

11. Simper D, Stalboerger PG, Panetta CJ, Wang S, Caplice NM. Smooth muscle progenitor cells in human blood. Circulation. 2002;106(10): $1199-1204$.

12. Harraz M, Jiao C, Hanlon HD, Hartley RS, Schatteman GC. CD34blood-derived human endothelial cell progenitors. Stem Cells. 2001; 19(4):304-312.

13. Yamashita H, Ichijo H, Grimsby S, Morén A, ten Dijke P, Miyazono K. Endoglin forms a heteromeric complex with the signaling receptors for transforming growth factor-beta. J Biol Chem. 1994;269(3):1995-2001.

14. Cheifetz S, Bellón T, Calés C, et al. Endoglin is a component of the transforming growth factor-beta receptor system in human endothelial cells. J Biol Chem. 1992;267(27):19027-19030.

15. Bernabeu C, Conley BA, Vary CP. Novel biochemical pathways of endoglin in vascular cell physiology. J Cell Biochem. 2007;102(6): $1375-1388$.

16. Kapur NK, Wilson S, Yunis AA, et al. Reduced endoglin activity limits cardiac fibrosis and improves survival in heart failure. Circulation. 2012;125(22):2728-2738.

17. van Laake LW, van den Driesche S, Post S, et al. Endoglin has a crucial role in blood cell-mediated vascular repair. Circulation. 2006;114(21): 2288-2297.

18. Fonsatti E, Nicolay HJ, Altomonte M, Covre A, Maio M. Targeting cancer vasculature via endoglin/CD105: a novel antibody-based diagnostic and therapeutic strategy in solid tumours. Cardiovasc Res. 2010; $86(1): 12-19$

19. Cui S, Liu JH, Song XT, et al. A novel stent coated with antibodies to endoglin inhibits neointimal formation of porcine coronary arteries. Biomed Res Int. Epub 2014 May 4.

20. Li HH, Kedar V, Zhang C, et al. Atrogin-1/muscle atrophy F-box inhibits calcineurin-dependent cardiac hypertrophy by participating in an SCF ubiquitin ligase complex. J Clin Invest. 2004;114(8):1058-1071.

21. Ma X, Hibbert B, Dhaliwal B, et al. Delayed re-endothelialization with rapamycin-coated stents is rescued by the addition of a glycogen synthase kinase-3beta inhibitor. Cardiovasc Res. 2010;86(2):338-345.

22. Steigerwald K, Merl S, Kastrati A, et al. The pre-clinical assessment of rapamycin-eluting, durable polymer-free stent coating concepts. Biomaterials. 2009;30(4):632-637.

23. Schwartz RS, Huber KC, Murphy JG, et al. Restenosis and the proportional neointimal response to coronary artery injury: results in a porcine model. J Am Coll Cardiol. 1992;19(2):267-274.

24. Hong YJ, Jeong MH, Lee SR, et al. Anti-inflammatory effect of abciximab-coated stent in a porcine coronary restenosis model. J Korean Med Sci. 2007;22(5):802-809.

25. Moukarbel GV, Burket MW. Paclitaxel-eluting stents for the treatment of femoropopliteal arterial stenoses: focus on the Zilver PTX drug-eluting peripheral stent. Expert Rev Med Devices. 2015;12(2):157-162.

26. Nakamura D, Lee $Y$, Yoshimura $T$, et al. Different serial changes in the neointimal condition of sirolimus-eluting stents and paclitaxel-eluting stents: an optical coherence tomographic study. EuroIntervention. 2014;10(8):924-933.

27. Pfisterer ME. Late stent thrombosis after drug-eluting stent implantation for acute myocardial infarction: a new red flag is raised. Circulation. 2008;118(11):1117-1119.

28. Ertaş G, van Beusekom HM, van der Giessen WJ. Late stent thrombosis, endothelialisation and drug-eluting stents. Neth Heart J. 2009; 17(4):177-180. 
29. Houtgraaf JH, Duckers HJ. Endothelial progenitor cell (EPC) capture to aid vascular repair following coronary stenting: a new frontier in stent technology? EuroIntervention. 2008;4(Suppl C):C67-C71.

30. Peichev M, Naiyer AJ, Pereira D, et al. Expression of VEGFR-2 and AC133 by circulating human CD34(+) cells identifies a population of functional endothelial precursors. Blood. 2000;95(3):952-958.

31. Valluru M, Staton CA, Reed MW, Brown NJ. Transforming growth factor- $\beta$ and endoglin signaling orchestrate wound healing. Front Physiol. 2011;2:89.

32. Lastres P, Letamendía A, Zhang H, et al. Endoglin modulates cellular responses to TGF-beta 1. J Cell Biol. 1996;133(5):1109-1121.

33. Park S, Dimaio TA, Liu W, Wang S, Sorenson CM, Sheibani N. Endoglin regulates the activation and quiescence of endothelium by participating in canonical and non-canonical TGF- $\beta$ signaling pathways. J Cell Sci. 2013;126(Pt 6):1392-1405.
34. Anderson P, Carrillo-Gálvez AB, García-Pérez A, Cobo M, Martín F. CD105 (endoglin)-negative murine mesenchymal stromal cells define a new multipotent subpopulation with distinct differentiation and immunomodulatory capacities. PLoS One. 2013;8(10):e76979.

35. van Beusekom HM, Ertaş G, Sorop O, Serruys PW, van der Giessen WJ. The Genous ${ }^{\mathrm{TM}}$ endothelial progenitor cell capture stent accelerates stent re-endothelialization but does not affect intimal hyperplasia in porcine coronary arteries. Catheter Cardiovasc Interv. 2012;79(2):231-242.

36. Liehn EA, Schober A, Weber C. Blockade of keratinocyte-derived chemokine inhibits endothelial recovery and enhances plaque formation after arterial injury in ApoE-deficient mice. Arterioscler Thromb Vasc Biol. 2004;24(10):1891-1896.

37. Li J, Li D, Gong F, Jiang S, Yu H, An Y. Anti-CD133 antibody immobilized on the surface of stents enhances endothelialization. Biomed Res Int. Epub 2014 Mar 10.

\section{Publish your work in this journal}

Drug Design, Development and Therapy is an international, peerreviewed open-access journal that spans the spectrum of drug design and development through to clinical applications. Clinical outcomes, patient safety, and programs for the development and effective, safe, and sustained use of medicines are a feature of the journal, which has also been accepted for indexing on PubMed Central. The manuscript management system is completely online and includes a very quick and fair peer-review system, which is all easy to use. Visit http://www.dovepress.com/testimonials.php to read real quotes from published authors.

Submit your manuscript here: http://www.dovepress.com/drug-design-development-and-therapy-journal 